\title{
Abnormal Eyes in Wild Gammarus zaddachi Sexton.
}

\author{
By
}

\section{R. Bassindale, M.Sc.}

With 2 Figures in the Text.

DURING the course of a biological survey of the Tay Estuary collections of the species of Amphipoda found in the tidal zone were made from Bridge of Earn, near the limit of tidal waters in the River Earn, down to the confluence of the Rivers Earn and Tay, and thence to Tayport, near the sea. Between Newburgh and Bridge of Earn (from 23 to 32 miles from the sea) the only Amphipoda recorded were 198 specimens of Gammarus and one specimen of Melita palmata (Mont.). The water in this part of the Estuary, although tidal, is for the most part fresh, attaining at Newburgh at high tide an average salinity of only 3 or $4 \mathrm{gm}$. per $1000 \mathrm{gm}$.

Four collecting stations were investigated in the zone described and all the Gammarus were identified by Mrs. Sexton as G. zaddachi Sexton,

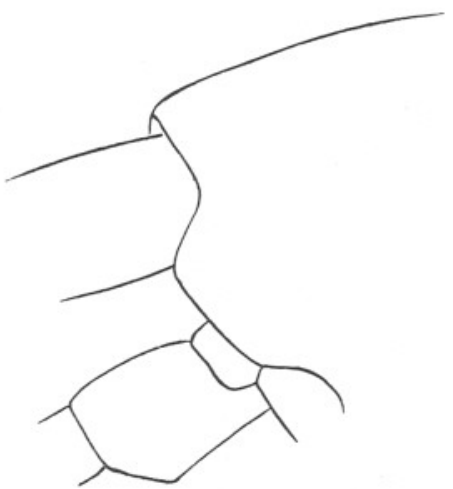

Fig. 1.

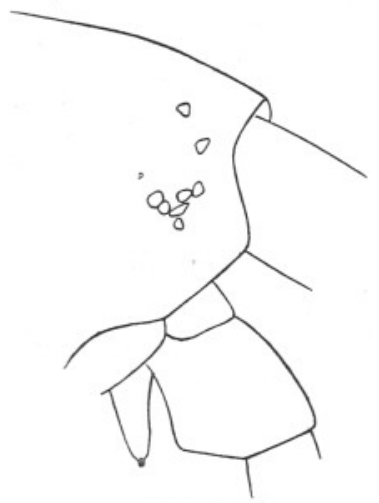

FIG. 2.

a brackish-water species described by Mrs. Sexton herself (1). Of these 198 specimens, four were observed to have abnormal eyes. Although this condition has been previously described from a Laboratory strain of $G$. chevreuxi (2) this is the first occasion on which wild specimens have been recorded with similar abnormalities. 
Of the four individuals, No. 1 was taken at the highest station at Bridge of Earn, and No. 2 was found at the second station some 3 miles lower down the Estuary. Nos. 3 and 4 both occurred at Newburgh, the lowest station at which $G$. zaddach $i$ was found.

Specimen No. 1 is small, measuring about $5 \mathrm{~mm}$. along the dorsal line. Both eyes are irregular, the left being rounded instead of reniform with the margin indented: the right eye is roughly triangular, very similar in shape to the one figured by Sexton (2) (Text-fig. 7, p. 356).

Specimen No. 2 is slightly larger ( $c a 7 \frac{1}{2} \mathrm{~mm}$.) and is remarkable in having only one eye developed —on the right side-practically normal in size and shape. There is no trace of an eye on the left side (Fig. 1).

Specimen No. 3 is the largest $(15 \mathrm{~mm}$.) and has suffered damage after capture. The eyes, however, show distinct irregularities in size (the right being much smaller than the left), in shape and in the arrangement of the ommatidea.

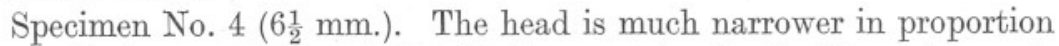
to the body measurements than in the normal animal. The right eye is degenerate, closely resembling the albino mutation of $G$. chevreuxi, and consists of a few scattered colourless cones (Fig. 2). The left eye was evidently large and pigmented in life, but has suffered damage and the exact details cannot be determined.

\section{SUMMARY.}

Of 198 specimens of Gammarus zaddachi collected in the Estuaries of the Rivers Earn and Tay four individuals had abnormal eyes. This is the first record of abnormal eyes in wild specimens of a Gammarus species, although Laboratory strains of $G$. chevreuxi have developed them.

The investigation described in this paper was carried out as part of the programme of the Water Pollution Research Board of the Department of Scientific and Industrial Research, and is published by permission of the Department. My thanks are due to Dr. E. J. Allen and to Mrs. E. W. Sexton for their assistance in preparing the paper.

\section{REFERENCES.}

1. Sexton, E. W. Some Brackish Water Amphipoda from the Mouths of the Weser and the Elbe and from the Baltic. Proc. Zool. Soc., Lond., 1912, p. 656.

2. Sexton, E. W. Degeneration and loss of the eye in the Amphipod Gammarus chevreuxi Sexton, Part I. Journ. Mar. Biol. Assoc., N.S., Vol. XVIII, No. 1, 1932, p. 355. 